\title{
Recruitment into psychiatry: views of consultants in Scotland
}

\section{AIMS AND METHOD}

By use of a postal survey we sought to determine attitudes and beliefs about recruitment to psychiatry. Members of the Scottish Division of the Royal College of Psychiatrists were asked to complete a questionnaire asking their views on the importance of various factors in relation to recruitment $(n=387)$.

\section{RESULTS}

Response rates were low from nonconsultants and we focused on the views of the 212 consultants (55\%) who responded. The perceived low status of psychiatry among other doctors and the belief that individuals with psychiatric disorders are difficult to deal with emerged as the two most important factors seen to affect recruitment. Improving undergraduate teaching in psychiatry was deemed important in enhancing recruitment.

\section{CLINICAL IMPLICATIONS}

Dealing with stigma, within and outwith the profession, and improving undergraduate exposure to psychiatry may be important in recruiting doctors to psychiatry.
Concern about recruitment and retention of psychiatrists is longstanding. The Royal College of Psychiatrists' annual census has consistently revealed consultant vacancy rates between $10-15 \%$, with general adult psychiatry and more recently, child and adolescent psychiatry (in Scotland at least), being particularly badly afflicted (Royal College of Psychiatrists, 2002). Over the years this has been highlighted by a number of authors, most recently by Pidd (2003). This is not merely an issue within the National Health Service (NHS) in the UK, but is an international problem as highlighted for example by Malhi et al (2003) in Australia, Strebel et al (2000) in Germany and Feifel et al (1999) in the USA.

In the autumn of 2003 a number of factors prompted us to carry out a survey exploring recruitment and retention issues with psychiatrists in Scotland. These included the advent of a new mental health Act (Mental Health (Care and Treatment) (Scotland) Act 2003) and the review of mental health services in Scotland commissioned by the Scottish Executive (Grant, 2004).

\section{Method}

Following a literature review, a questionnaire was designed to obtain information from psychiatrists in Scotland about recruitment and retention that might aid workforce planning. We have previously reported the data from this survey on retirement intentions (Eagles et al, 2005)

In the section on recruitment, psychiatrists were asked which of a number of beliefs and attitudes they felt were important in influencing the career choices of medical students and junior doctors in relation to psychiatry. The questionnaire is available in full from the authors but in broad terms the following five questions about recruitment were asked:

- What beliefs and attitudes are important in influencing the career choice of medical students as junior doctors?
- What influenced your own choice of psychiatry as a career?

- At what stage did you choose psychiatry as a career?

- How would you improve recruitment to psychiatry?

- Do you have difficulty recruiting to your sub-specialty in psychiatry?

The first two questions asked respondents to state views on whether a number of factors influence recruitment in a 'yes' or 'no' forced choice format. These covered a range of topics, including the perceived difficulty of dealing with and treating individuals with psychiatric disorders, the status of psychiatry within medicine and within society at large, the legal framework in which psychiatry is practised and undergraduate exposure to psychiatry. In addition there was space to expand on responses and to volunteer additional factors felt to be of importance by the respondents.

Questionnaires were posted in summer 2003 to all members of the College listed as working in Scotland at the time. All grades of psychiatrist on the College list were surveyed. A reminder was sent in a subsequent routine College mailing. Retired consultants whose names still appeared on College records were included.

\section{Results}

Of 387 psychiatrists in consultant posts in Scotland in September 2003, 212 (55\%) responded. The response rate from junior doctors and non-consultant career grades was considerably lower with only 47 out of 513 responding (9\%). Ten of the consultant respondents had retired.

In view of the poor response rate from juniors and non-consultant career grade doctors we have focused our analysis on the responses of consultants. These responses are summarised in Tables $1-3$.

The perceived low status of psychiatry among other medical professionals and the perceived difficulty in dealing with individuals with psychiatric disorders clearly emerged as the two most important factors in the forced 
Table 1. Consultants' responses to the question: 'Are the following beliefs and attitudes important factors in influencing the career choice of medical students or junior doctors?'

original papers
Answering

yes, $n(\%)$

Psychiatry has low status among other medical

professionals

Psychiatric patients are difficult to deal with

$161(76)$

Psychiatry has low status among the general

$139(66)$

public

The threat of suicide/homicide enquiries is ever

present

Psychiatry has low status among politicians

Psychiatry is poorly resourced

Psychiatry is unscientific and conceptually weak

Psychiatric disorders aren't really treatable

The legal framework is a hassle

Psychiatry is too psychosocial in its approach

Psychiatry is less financially rewarding

Psychiatry has fewer opportunities for private practice

Psychiatry is too biological in its approach

Table 2. Consultants' views on specific factors adversely

influencing recruitment

Respon-

dents, $n$

(\%)

Closed options

Single factor deemed most important

Psychiatry has low status among other

medical professions

$86(41)$

Psychiatry is poorly resourced

Psychiatry has low status among the

general public

$18(8)$

Psychiatric patients are difficult to deal with

$12(6)$

Poor undergraduate exposure to psychiatry

12 (6)

All other options

$64(30)$

Open question

Other factors deemed important

Inadequate undergraduate exposure

to psychiatry

39

Overwork

Media portrayal of psychiatry

Low morale among consultants

Lack of interaction with the rest

of medicine

The new Mental Health Act

choice section of the questionnaire (Table 1). Of the factors emerging from the open part of the questionnaire permitting respondents to suggest other relevant factors, 39 respondents spontaneously highlighted the importance of undergraduate teaching (Table 2). This was also one of the top five factors rated as important by respondents in recruiting themselves to psychiatry (Table 3). The most important factor to emerge from this section of the questionnaire was 'interest in and concern for the mentally ill', rated as important by $90 \%$ of respondents.
Table 3. Factors influencing consultants to become psychiatrist

\begin{tabular}{lc} 
Top five factors & $\begin{array}{c}\text { Respondents, } \\
n(\%)\end{array}$ \\
\hline Interest in, and concern for, the mentally ill & $176(83)$ \\
More interested in people than diseases & $137(65)$ \\
Greater interest in social aspects of medicine & $133(63)$ \\
Ability to tolerate ambiguity & $129(61)$ \\
Good undergraduate exposure to psychiatry & $119(56)$ \\
\hline
\end{tabular}

When asked to stipulate the single most important factor influencing their own choice of psychiatry, again 'Interest and concern for the mentally ill' topped the list with 53 respondents (20\%) opting for this, with 'good undergraduate exposure to psychiatry' in second place with 34 respondents (13\%).

With regard to timing of choice of psychiatry as a career, only $9 \%$ went into medical school having made this choice. Of the remainder, almost equal numbers made the decision as an undergraduate (or early in house officer jobs) or when working in another specialty. Recruitment difficulties were perceived to be much worse in general adult and in child and adolescent psychiatry than in the other specialties.

\section{Discussion}

Presumably in part because the contact addresses held by the College for non-consultants were not contemporary, the response rate from these psychiatrists was very low. We thus reported only the views of consultants; their $55 \%$ response rate at least provides a reasonably representative sample of consultants working in Scotland. Our questionnaire was based on factors identified in the literature as being potentially relevant to recruitment. This had the limitation of omitting factors which may be currently important, such as the impact of changing mental health legislation or the advent of Modernising Medical Careers (although some respondents commented upon these topics in the open question sections of the questionnaire).

It is perhaps unsurprising (but certainly reassuring) that 'interest in and concern for the mentally ill' was rated as the most important factor in motivating respondents to enter psychiatry. Although interest in social and interpersonal aspects of medicine emerged also as positive factors for recruitment, psychiatry was not seen as either too psychosocial or too biological in its approach (Table 1).

The theme of stigma emerged as an important impediment to recruitment, both within and outwith the medical profession. The perceived low status of psychiatry among those in the medical profession (regarded as the single most important factor affecting recruitment) and among the general public, coupled with the perception that individuals with psychiatric disorders are difficult to deal with, seem to support the importance of stigmatising attitudes. Anti-stigma campaigns may not have adequately targeted attitudes among other healthcare professionals and students. 
Respondents highlighted the importance of undergraduate education. It was in response to these views that we established the Scottish Division Undergraduate Student Teaching And Recruitment Group (S-DUSTARG) with the remit of enhancing medical student teaching and thus hopefully improving recruitment into psychiatry. We have previously reviewed some of the factors which may influence whether medical students become psychiatrists (Eagles et al, 2007), and other authors have discussed the importance of undergraduate teaching (Sierles \& Taylor, 1995; Brockington \& Mumford, 2002; Pidd, 2003).

Excellence in psychiatric undergraduate teaching may help to offset some of the apparently prevalent negative attitudes among the medical profession, as mentioned above.

Finally, the timing of respondents' decisions to become psychiatrists is noteworthy. As other surveys attest (Cameron \& Persad, 1984; Goldacre et al, 2005), many doctors are at a postgraduate stage before deciding upon a psychiatric career. With the advent of Modernising Medical Careers, some young doctors will be exposed to psychiatry during their foundation years, but only a small proportion will do so before deciding on the specialty they wish to pursue in run-through training. Especially since it seems likely that changes of specialty will be more difficult within Modernising Medical Careers, the possible effects of this early career choice upon recruitment into psychiatry will need to be monitored.

\section{Declaration of Interest}

None.

\section{Acknowledgements}

We are grateful to all respondents. These findings were previously presented by T.M.B. at a meeting of the
Scottish Division of the Royal College of Psychiatrists. Lana Hadden assisted with the secretarial work.

original

papers

\section{References}

BROCKINGTON, I. F. \& MUMFORD, D. B. medical schools. British Journal of (2002) Recruitment into psychiatry. Psychiatry, 186, 158-164. British Journal of Psychiatry, 180, 307312.

CAMERON, P. \& PERSAD, E. (1984) Recruitment into psychiatry: a study of the timing and process of choosing psychiatry as a career. Canadian Journal of Psychiatry, 29, 676-680.

EAGLES, J. M., ADDIE, K. \& BROWN,T. (2005) Retirement intentions of consultant psychiatrists. Psychiatric Bulletin, 29, 374-376.

EAGLES, J. M.,WILSON, S., MURDOCH, J. M., et al (2007) What impact do undergraduate experiences have upon recruitment into psychiatry? Psychiatric Bulletin, 31,70-72.

FEIFEL, D., MONTIER, C.Y. \& SWERDLAW, N. F. (1999) Attitudes toward psychiatry as a prospective career among students entering medical school. American Journal of Psychiatry, 156, 1397-1402

GOLDACRE, M. J., TURNER, G., FAZEL, S., et al (2005) Career choices for psychiatry: national surveys of graduates of 1974-2000 from UK

GRANT, S. (2004) Towards Implementation of the Mental Health (Care and Treatment) (Scotland) Act

2003. Final Report. Scottish Executive Publications.

MALHI, G. S., PARKER, G. B., PARKER, K., et al (2003) Attitudes towards psychiatry among students entering medical school. Acta Psychiatrica Scandinavica, 107, 424-429.

PIDD, S. A. (2003) Recruiting and retaining psychiatrists. Advances in PsychiatricTreatment, 9, 405-411.

ROYAL COLLEGE OF PSYCHIATRISTS (2002) Annual Census of Psychiatric Staffing 2001. Royal College of Psychiatrists.

SIERLES, F. S. \& TAYLOR، M. A. (1995) Decline of US medical student career choice of psychiatry and what to do about it. American Journal of Psychiatry, 152, 1416-1426.

STREBEL, B., OBLADEN, M., LEHMANN E., et al (2000) German medical students'attitudes toward psychiatry. Nervenarzt, 71, 205-212

*Tom M. Brown Consultant Liaison Psychiatrist, Western Infirmary, Dumbarton Road, Glasgow G116NT. Email:Tom.Brown@glacomen.scot.nhs.uk, Karen Addie Policy Manager, Scottish Division of the Royal College of Psychiatrists, Edinburgh, John M. Eagles Consultant Psychiatrist, Royal Cornhill Hospital, Aberdeen 